\title{
BK polyomavirus nephropathy in two kidney transplant patients with distinct diagnostic strategies for BK virus and similar clinical outcomes: two case reports
}

\author{
Ana Luisa Figueira Gouvêa ${ }^{1,2^{*}}$, Rachel Ingrid Juliboni Cosendey', Ana Lucia Rosa Nascimento², \\ Fabiana Rabe Carvalho', Andrea Alice Silva ${ }^{1,2}$, Heleno Pinto de Moraes ${ }^{3}$, Mayra Carrijo Rochael ${ }^{2}$, \\ Rafael Brandão Varella', Stephanie Gomes Almeida ${ }^{4}$, Jorge Reis Almeida ${ }^{1}$ and Jocemir Ronaldo Lugon ${ }^{1}$
}

\begin{abstract}
Background: BK polyomavirus-associated nephropathy is an important cause of post-transplantation renal failure. We present two cases of BK polyomavirus-associated nephropathy who were submitted to contrasting strategies of clinical follow-up to BK polyomavirus reactivation, but progressed to a similar final outcome.

Case presentation: Case 1 is a 37-year-old white man whose graft had never presented a good glomerular filtration rate function, with episodes of tacrolimus nephrotoxicity, and no urinary monitoring for BK polyomavirus; stage B BK polyomavirus-associated nephropathy was diagnosed by biopsy at 14 months post-transplant. Despite clinical treatment (dosage decrease and immunosuppressive drug change), he progressed to stage C BK polyomavirus-associated nephropathy and loss of graft function 30 months post-transplant. Case 2 is a 49-year-old mulatto man in his second renal transplantation who was submitted to cytological urinary monitoring for BK polyomavirus; he presented early, persistent, and massive urinary decoy cell shedding and concomitant tacrolimus nephrotoxicity. Even with decreasing immunosuppression, he developed BK polyomavirus-associated nephropathy 1-year post-transplant. Loss of graft function occurred 15 months post-transplant.
\end{abstract}

Conclusions: Cytological urinary monitoring was an efficient strategy for monitoring BK virus reactivation. Decoy cell shedding may be related to BK polyomavirus-associated nephropathy when extensive and persistent. The presence of associated tacrolimus nephrotoxicity may be a confounding factor for the clinical diagnosis of BK polyomavirus-associated nephropathy.

Keywords: BK polyomavirus, BK-associated nephropathy, Decoy cell, Urinary monitoring, Renal transplant, Allograft dysfunction infectious disease

\section{Background}

BK polyomavirus-associated nephropathy (BKVAN) affects up to $15 \%$ of renal transplant recipients and is an important cause of graft failure, due to insidious inflammatory destruction of the renal tissue [1-5]. Monitoring of BK polyomavirus (BKV) infection in these patients is required

\footnotetext{
* Correspondence: anafigueira@id.uff.br

'Laboratório Multiusuário de Apoio à Pesquisa em Nefrologia e Ciências Médicas (LAMAP), Department of Clinical Medicine, Universidade Federal Fluminense, Rua Marquês do Paraná, 303, Niterói 24033-900, Rio de Janeiro, Brazil

${ }^{2}$ Department of Pathology, Universidade Federal Fluminense, Niterói, Brazil Full list of author information is available at the end of the article
}

for early detection of reactivation. It can be performed by detection of decoy cells (DC) in urine or detection of virus in plasma and urine using polymerase chain reaction (PCR) tests [5-10]. BKVAN diagnosis depends on specific morphological findings in allograft biopsy or detection of small and cohesive aggregates of polyomavirus called Haufenpolyomavirus in ultrastructural urine tests [11-13].

Many risk factors are involved in BKV reactivation [13-15], but the identification of patients who have high risk to develop BKVAN remains a challenge [16]. Specific antiviral treatments for BKV are not available 
$[14,17]$. The absence of a standard protocol for BKV infection treatment makes clinical management of these patients difficult.

We present two cases of BKVAN. Patient 1 was not monitored for BKV reactivation, while patient 2 was regularly monitored for BKV by urine testing for the presence of DC, which led to early diagnosis of viral reactivation. Both patients lost graft function due to BKVAN approximately a year after transplantation.

\section{Case presentation}

\section{Case 1}

A 37-year-old white man underwent kidney transplant in July 2013 due to hypertension nephropathy. In the first postoperative (PO) 5 months, his glomerular filtration rate estimated by the Modification of Diet in Renal Disease Study equation (MDRD) [18] ranged between 45 and $49 \mathrm{~mL} /$ minute per $1.73 \mathrm{~m}^{2}$ (Fig. 1). In PO month 6, he was administered prednisone $5 \mathrm{mg} /$ day, mycophenolate mofetil (MMF) $1440 \mathrm{mg} /$ day, and tacrolimus $6 \mathrm{mg}$ twice a day. The tacrolimus was reduced from $12 \mathrm{mg}$ to $6 \mathrm{mg} /$ day and MMF was substituted with sirolimus ( $3 \mathrm{mg} /$ day). In PO month 10, there were clinical signs of tacrolimus nephrotoxicity and the dosage was further decreased to $4 \mathrm{mg} /$ day. A graft biopsy was performed in PO month 14, due to continuous decreasing renal function. The biopsy revealed stage B BKVAN characterized by: epithelial tubular necrosis foci; many epithelial cells with basophilic intranuclear inclusions presenting diffusely in the core, especially in the medulla; patchy and moderate interstitial infiltrate with predominance of lymphocytes; a microabscess of neutrophils involving medullar tubules; edema, especially in the medulla; patchy stromal bleeding; few foci of mild tubulitis (maximum two inflammatory cells per tubular cross-section); tubular atrophy; interstitial fibrosis in $<10 \%$ of renal cortex (Fig. 2a); and arteriolosclerosis with some hyalinosis. Many tubular epithelial cells were positive for Simian virus 40 large T antigen (SV40 T-ag). There were no signs of transplant glomerulopathy or vasculopathy/vasculitis. Tacrolimus was substituted with MMF $720 \mathrm{mg} /$ day. Our patient presented episodes of bacterial infection in his respiratory tract (PO month 27) and skin (PO month 29), when two sessions of hemodialysis were required. A second graft biopsy was performed in PO month 30, showing extensive interstitial fibrosis $(>90 \%$ renal cortex) and inflammatory cell infiltration ( $>50 \%$ renal cortex), mainly composed of lymphocytes (Fig. 2b). Some tubular cells in the medulla showed basophilic intranuclear inclusions. There were no signs of transplant glomerulopathy or vasculopathy and

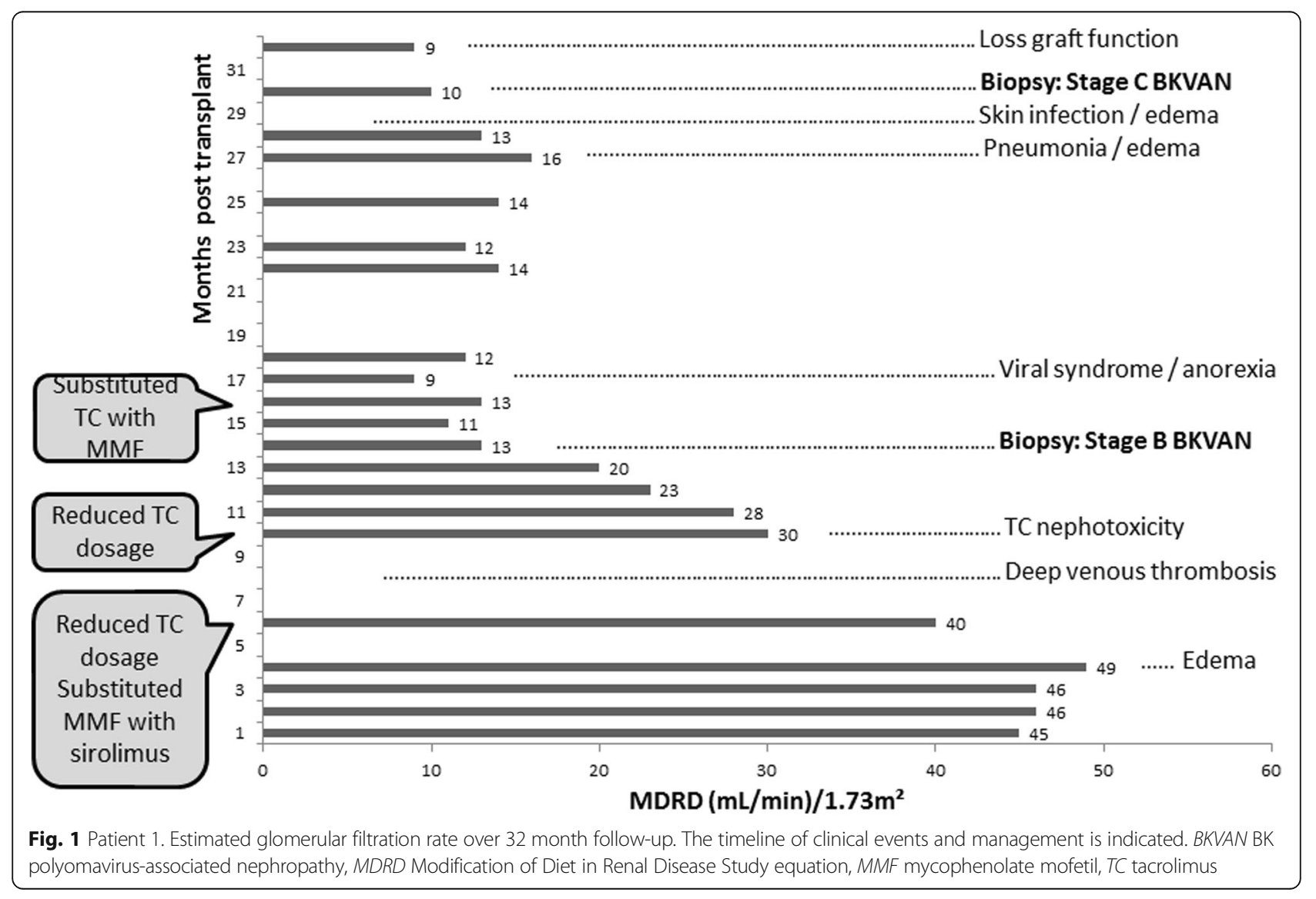






Fig. 2 Patient 1. Kidney allograft biopsy: a Stage B BK polyomavirus-associated nephropathy; b Stage C BK polyomavirus-associated nephropathy. Methenamine silver stain

complement component $4 \mathrm{~d}(\mathrm{C} 4 \mathrm{~d})$ was negative. There was weak nuclear positivity for SV40 T-ag in a few tubular epithelial cells in the cortex and medulla. The diagnosis was stage C BKVAN. He was returned to the hemodialysis program.

\section{Case 2}

A 49-year-old mulatto man underwent kidney transplant in June 2015 due to autosomal dominant polycystic kidney disease. He underwent a previous kidney transplant in 2011 and spent 3 years on dialysis between the two transplants. In PO month 2, his serum tacrolimus level was $26.7 \mathrm{ng} / \mathrm{mL}$. He was administered prednisone $(15 \mathrm{mg} /$ day), sirolimus ( $3 \mathrm{mg} /$ day), and tacrolimus ( $2 \mathrm{mg}$ twice a day). Tacrolimus was decreased from $4 \mathrm{mg}$ to $2 \mathrm{mg}$ /day (Fig. 3). He was submitted to biweekly urinary monitoring for BKV (screening for DC in urine sediment). Urinary $\mathrm{DC}$ were detected in $\mathrm{PO}$ month 3 . From then on, all urine samples were strongly positive for $\mathrm{DC},>10 /$ high power field (HPF), with the smears presenting a dirty background, cellular debris, many leukocytes and, in some samples, cellular casts with nuclei showing features of polyomavirus infection (Fig. 4). An ultrastructural study of urine sediment revealed abundant icosahedral viral particles measuring approximately $40 \mathrm{~nm}$ in diameter, either intranuclear or in the cytosol, as single particles, small

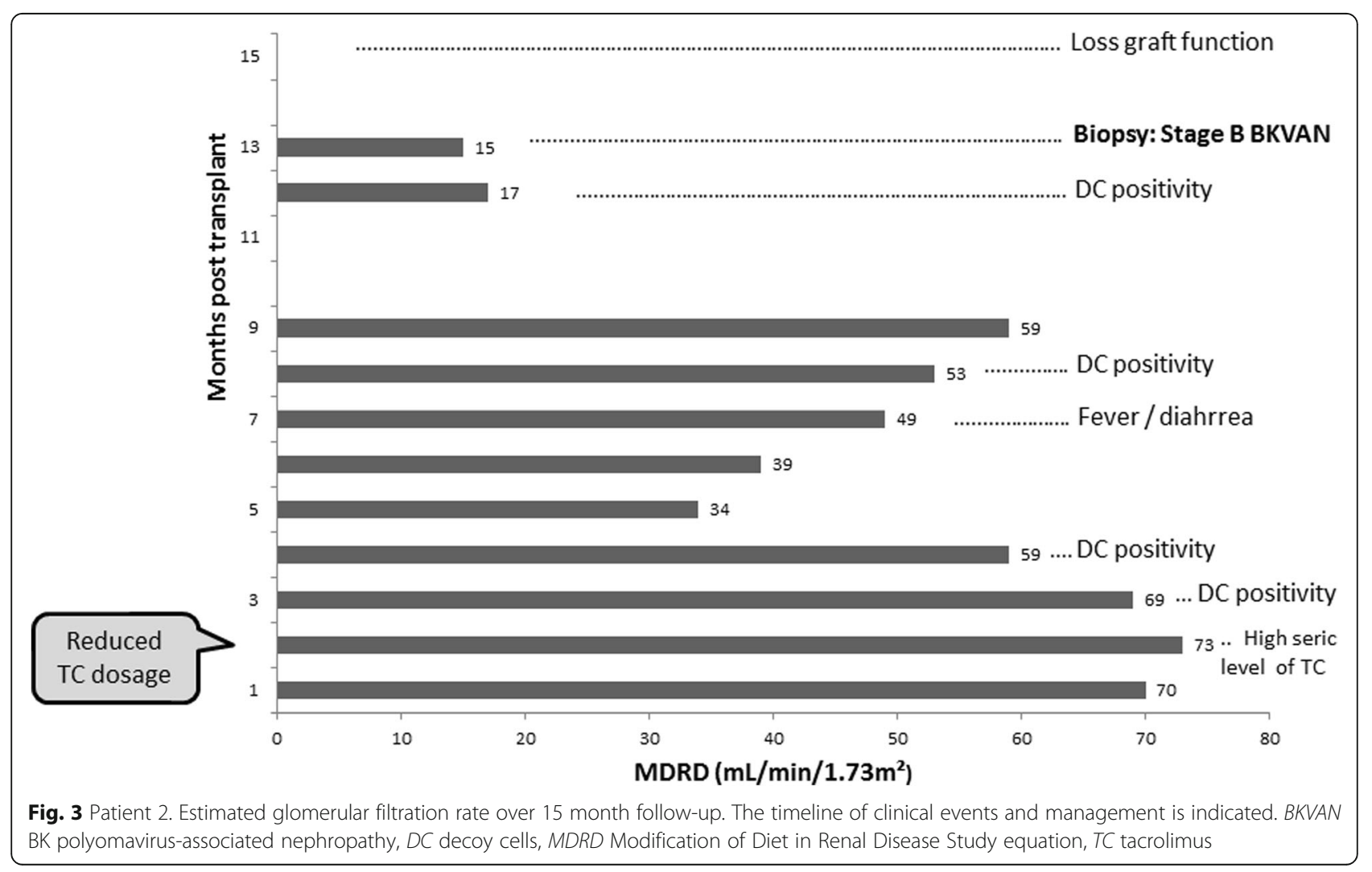




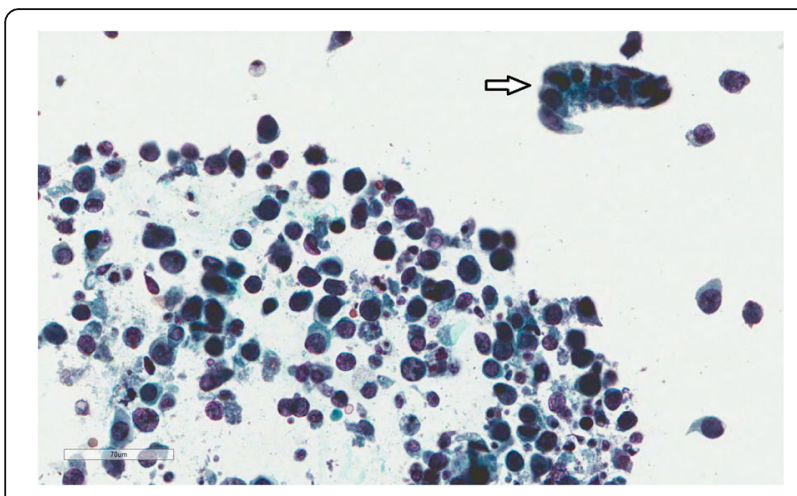

Fig. 4 Patient 2. Numerous decoy cells and a decoy cell cast (arrow) Papanicolaou stain

aggregates, or forming typical crystalline arrays, free or membrane-bound, or extracellular in continuity with the cell membrane (Fig. 5). In PO month 12, there was a sharp drop in renal function and a graft biopsy was performed. The histology revealed stage B BKVAN characterized by tubular cellular necrosis associated with many nuclear inclusions expressing SV40 T-ag (Fig. 6), present in both cortex and medulla, minimal interstitial inflammatory infiltrate, fibrosis and tubular atrophy, no tubulitis, and no transplant glomerulopathy or vasculopathy. There were no typical morphological signs of nephrotoxicity by tacrolimus. He returned to the hemodialysis program in PO month 15.

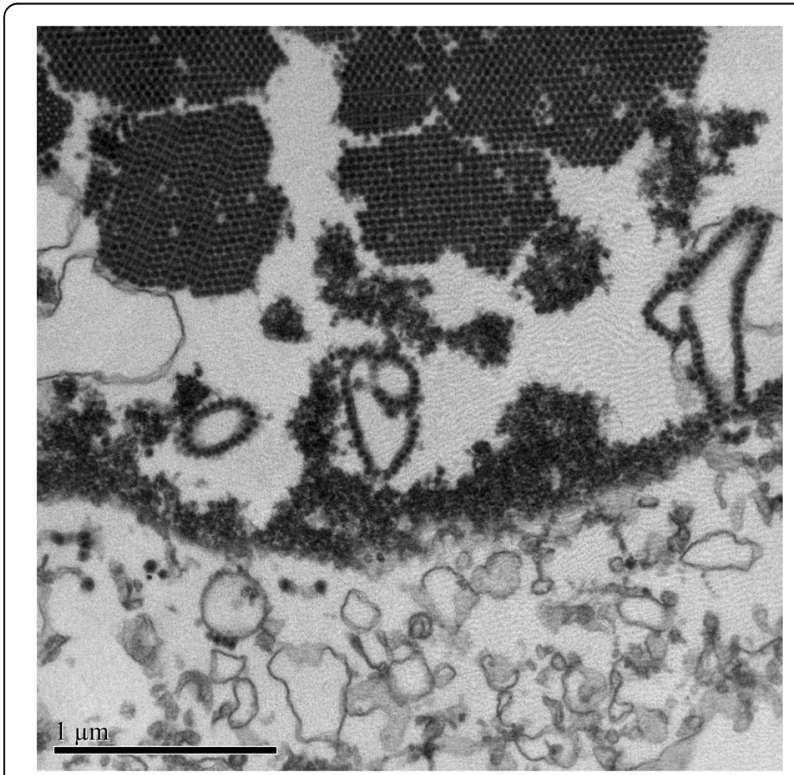

Fig. 5 Patient 2. Decoy cell ultrastructure: chromatin clumps at nuclear periphery and intranuclear spherical virions arranged in crystalloid array

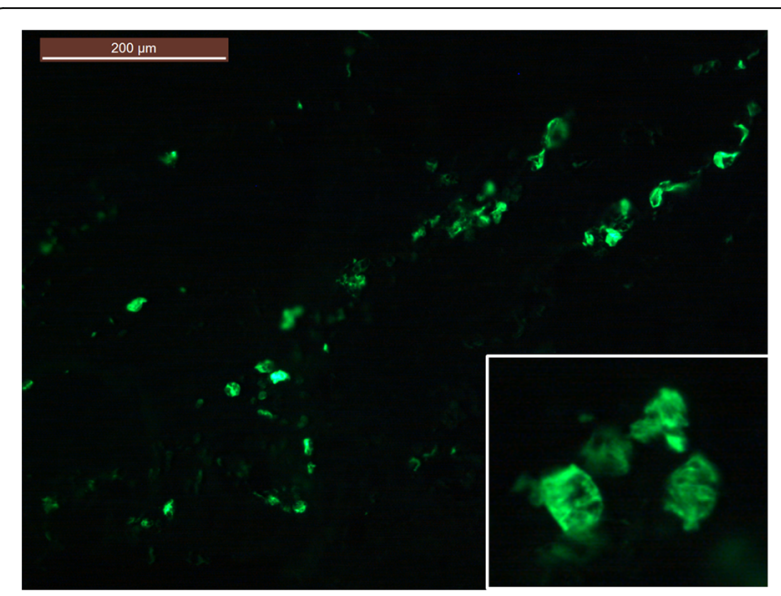

Fig. 6 Patient 2. Kidney allograft biopsy: Simian virus 40 large T antigen nuclear staining in renal tubular cells. Inset: nuclear detail (immunofluorescence)

\section{Discussion}

Effective and safe antiviral therapies for BKVAN are not available. The management of patients with BKV reactivation is a challenge because there is not a reliable and universally accepted protocol to follow.

The pathogenesis of BKVAN is multifactorial, with several known risk factors: immunosuppression (a general prerequisite); "high dose" of new drugs such as tacrolimus; pre-transplant use of antilymphocyte therapy and MMF use at baseline; tubular injury/regeneration and/or ische$\mathrm{mia} /$ reperfusion in allograft (since native kidneys are generally not involved); human leukocyte antigen (HLA) mismatches; recipient diabetes; previous acute rejection; recipient age >55 years; recipient race (white); and recipient gender (male) [4, 5, 14, 15, 19-21]. Both cases discussed here are male, presenting tacrolimus nephrotoxicity before BKVAN development. Higher blood levels of tacrolimus are associated with an increased incidence of BK viremia, which supports the notion that immunosuppression increases the risk of BKVAN [14]. Epithelial cell proliferative state in response to different forms of injury may increase BKV replication [15]. When their charts were reviewed, both patients presented previous tubular damage (multifocal epithelial necrosis) in their pre-implantation donor kidney biopsies.

Once BKVAN is diagnosed, definition of the presence of concurrent rejection can be very difficult to establish, because some morphological aspects may be shared by both conditions and they may co-occur [15, 22]. Some clues for BKVAN diagnosis are: a heterogeneous inflammatory reaction, sometimes minimal, present especially in the medulla and composed of mononuclear cells; polymorphonuclear leukocytes, which can be seen in response to urinary leakage from damaged tubules; and inconspicuous tubulitis and viral lesions restricted to the medulla 
[19]. On the other hand, in concurrent rejection there is abundant tubulitis, cortical inflammatory infiltrates (more pronounced in areas without viral inclusions), transplant endarteritis, glomerulitis, glomerulopathy, sclerosing vasculopathy, and C4d deposition along the peritubular capillaries [19, 23]. Patient 1 exhibited interstitial edema and hemorrhagic foci. Although no morphological criteria for rejection (Banff classification) were present in this sample, it would be very difficult to definitely rule out this association.

It is difficult to make predictions about the progression of BKVAN. The risk of graft loss function in stage A is $<10 \%$, in stage B close to $50 \%$, and in stage C $>80 \%$ [5]. Both patients were diagnosed at stage $B$.

Tacrolimus is a calcineurin inhibitor and some histological lesions have been associated with its chronic use, such as striped interstitial fibrosis, tubular atrophy, medial arteriolar hyalinosis, and tubular microcalcification [24]. Tacrolimus may have played a role in the fibrosis observed in the graft biopsies of both patients.

Patient 2 presented early DC shedding. Considering that he had two renal transplants in 4 years, we wondered if BKV reactivation could be linked to his first kidney transplant. A previous transplant, in general, has not been confirmed as a risk factor for BKVAN [21]. However, retransplantation after a graft loss due to BKVAN may be an important factor [5]. Unfortunately, the reason for the loss of his first graft is unknown.

PCR tests for BKV in urine and plasma have higher positive predictive value for BKVAN than urinary cytology. However, urinary cytology is a low cost and simple method for BKV screening, with negative predictive value for BKVAN of $100 \%[5,25]$. Some authors value the number of DC $(>10 / \mathrm{HPF})$, presence of a necro-inflammatory background in urine containing DC, persistent DC shedding (over 6 weeks), and detection of DC casts to identify patients with possible active BKVAN $[1,26,27]$. Patient 2 presented all of these characteristics, but we only had an unequivocal criterion to perform graft biopsy when a clear drop in renal function was detected. The choice of the ideal moment to perform a renal allograft biopsy in BKV infection is a matter of controversy. It is an invasive procedure, which requires strict indication. On the other hand, initial BKVAN can have an indolent presentation, with no clear allograft dysfunction [5]. The associated tacrolimus nephrotoxicity may have masked the real importance of BKV reactivation in the clinical scenario of patient 2.

Both patients were diagnosed with BKVAN at the end of the first year post-transplant. The diagnosis of viral reactivation was conceivably earlier in patient 2 , who was systematically monitored. In spite of that, the course of BKVAN in the two cases was similar. An early diagnosis can be very important to preserve the tissue from inflammation and fibrosis. It is unclear if the availability of an effective antiviral drug would have made a difference in the clinical course of these patients.

\section{Conclusions}

Urinary monitoring for DC is a simple and efficient strategy for routine screening of BKV reactivation. Early detection of BKV infection in patients who have undergone a renal transplant is crucial to identify patients demanding closer clinical supervision. The presence of massive and persistent DC shedding can indicate a high risk for BKVAN development, even if renal function is normal.

Tacrolimus nephrotoxicity is a common complication in patients who have undergone a renal transplant and may mask the real importance of BKV reactivation.

\section{Abbreviations}

BKV: BK polyomavirus; BKVAN: BK polyomavirus-associated nephropathy; C4d: Complement component 4d; DC: Decoy cells; HLA: Human leukocyte antigen; HPF: High power field; MDRD: Modification of Diet in Renal Disease Study equation; MMF: Mycophenolate mofetil; PCR: Polymerase chain reaction; PO: Postoperative; SV40 T-ag: Simian virus 40 large T antigen

\section{Acknowledgements}

This work was performed in the Department of Clinical Medicine and Department of Pathology, Universidade Federal Fluminense. We thank the Biology Institute of Universidade Federal Fluminense for allowing us to use the transmission electron microscope (JEM 1011) and the technical support biologist Alan Moraes for acquiring images. We also thank Anna Karoline Fausto da Silva for immunohistochemical stains of SV40 T-ag and Dr Paulo Alexandre Menezes, who was the attending physician of the cases.

\section{Funding \\ FAPERJ - Fundação de Amparo à Pesquisa do Estado do Rio de Janeiro. E- 26/111.702/2013.}

Availability of data and materials

Not applicable.

Authors' contributions

All authors contributed equally to drafting, revision, and preparation of the manuscript. All authors read and approved the final manuscript.

Competing interests

The authors declare that they have no competing interests.

\section{Consent for publication}

Written informed consent was obtained from the patients for publication of this case report and any accompanying images. A copy of the written consent is available for review by the Editor-in-Chief of this journal.

\section{Ethics approval and consent to participate}

All procedures used in this study were approved by the Ethics Committee of Universidade Federal Fluminense. Reference number 24490913.9.0000.5243 (trial: 506.290).

\section{Publisher's Note}

Springer Nature remains neutral with regard to jurisdictional claims in published maps and institutional affiliations.

\section{Author details}

'Laboratório Multiusuário de Apoio à Pesquisa em Nefrologia e Ciências Médicas (LAMAP), Department of Clinical Medicine, Universidade Federal Fluminense, Rua Marquês do Paraná, 303, Niterói 24033-900, Rio de Janeiro, Brazil. 'Department of Pathology, Universidade Federal Fluminense, Niterói, Brazil. ${ }^{3}$ Department of 
Pathology, Universidade do Estado do Rio de Janeiro, Rio de Janeiro, Brazil. ${ }^{4}$ Department of Preventive Medicine, Universidade Federal do Rio de Janeiro, Rio de Janeiro, Brazil.

Received: 22 January 2017 Accepted: 21 April 2017

Published online: 24 May 2017

\section{References}

1. Drachenberg RC, Drachenberg CB, Papadimitriou JC, Ramos E, Fink JC, Wali $R$, et al. Morphological spectrum of polyoma virus disease in renal allografts: diagnostic accuracy of urine cytology. Am J Transplant. 2001;1:373-81.

2. Bohl DL, Brennan DC. BK virus nephropathy and kidney transplantation. Clin J Am Soc Nephrol. 2007;2 Suppl 1:S36-46.

3. Kalvatchev Z, Slavov S, Shtereva M, Savova S. Reactivation of Polyomavirus hominis 1 (BKV) during pregnancy and the risk of mother-to-child transmission. J Clin Virol. 2008;43:328-9.

4. Nickeleit $\mathrm{V}$, Singh HK. Polyomaviruses and disease: is there more to know than viremia and viruria? Curr Opin Organ Transplant. 2015;20:348-58.

5. Hirsch HH, Randhawa P, AST Infectious Diseases Community of Practice. BK polyomavirus in solid organ transplantation. Am J Transplant. 2013;13 Suppl 4:179-88.

6. Gouvêa ALF, Cosendey RIJ, Carvalho FR, Varella RB, de Souza CF, Lopes PF, et al. Pilot Study of Early Monitoring Using Urinary Screening for BK Polyomavirus as a Strategy for Prevention of BKV Nephropathy in Kidney Transplantation. Transplant Proc. 2016:48:2310-4.

7. Thamboo TP, Jeffery KJM, Friend PJ, Turner GDH, Roberts ISD. Urine cytology screening for polyoma virus infection following renal transplantation: the Oxford experience. J Clin Pathol. 2007;60:927-30.

8. Bechert CJ, Schnadig VJ, Payne DA, Dong J. Monitoring of BK viral load in renal allograft recipients by real-time PCR assays. Am J Clin Pathol. 2010;133:242-50.

9. Chon WJ, Aggarwal N, Kocherginsky M, Kane B, Sutor J, Josephson MA. High-level viruria as a screening tool for BK virus nephropathy in renal transplant recipients. Kidney Res Clin Pract. 2016;35:176-81.

10. Costa C, Bergallo M, Astegiano S, Terlizzi ME, Sidoti F, Segoloni GP, et al. Monitoring of BK virus replication in the first year following renal transplantation. Nephrol Dial Transplant. 2008;23:3333-6.

11. Singh HK, Andreoni KA, Madden V, True K, Detwiler R, Weck K, et al. Presence of urinary Haufen accurately predicts polyomavirus nephropathy. J Am Soc Nephrol. 2009;20:416-27.

12. Singh HK, Reisner H, Derebail VK, Kozlowski T, Nickeleit V. Polyomavirus nephropathy: quantitative urinary polyomavirus-Haufen testing accurately predicts the degree of intrarenal viral disease. Transplantation. 2015;99:609-15.

13. Sawinski D, Goral S. BK virus infection: an update on diagnosis and treatment. Nephrol Dial Transplant. 2015;30:209-17.

14. Elfadawy N, Flechner SM, Liu X, Schold J, Tian D, Srinivas TR, et al. The impact of surveillance and rapid reduction in immunosuppression to control BK virus-related graft injury in kidney transplantation. Transpl Int. 2013;26:822-32

15. Jamboti JS. BK virus nephropathy in renal transplant recipients. Nephrology (Carlton). 2016;21:647-54

16. Thangaraju S, Gill J, Wright A, Dong J, Rose C, Gill J. Risk Factors for BK Polyoma Virus Treatment and Association of Treatment With Kidney Transplant Failure: Insights From a Paired Kidney Analysis. Transplantation. 2016;100:854-61

17. Funahashi Y, Kato M, Fujita T, Ishida S, Mori A, Gotoh M. Association Between the Polyomaviruses Titers and Decoy Cell Positivity Rates After Renal Transplantation. Transplant Proc. 2016;48:921-3.

18. Levey AS, Bosch JP, Lewis JB, Greene T, Rogers N, Roth D. A more accurate method to estimate glomerular filtration rate from serum creatinine: a new prediction equation. Modification of Diet in Renal Disease Study Group. Ann Intern Med. 1999;130:461-70

19. Nickeleit V, Hirsch HH, Zeiler M, Gudat F, Prince O, Thiel G, et al. BK-virus nephropathy in renal transplants-tubular necrosis, MHC-class II expression and rejection in a puzzling game. Nephrol Dial Transplant. 2000;15:324-32.

20. Hirsch HH, Knowles W, Dickenmann M, Passweg J, Klimkait T, Mihatsch MJ et al. Prospective study of polyomavirus type BK replication and nephropathy in renal-transplant recipients. N Engl J Med. 2002;347:488-96.

21. Dall A, Hariharan S. BK Virus Nephritis after Renal Transplantation. Clin J Am Soc Nephrol. 2008;3:S68-75.
22. Kawanishi K, Honda K, Koike J, Hattori M, Fuchinoue S, Tanabe K, et al. A Preliminary Study Into the Significance of Intrarenal Reflux in BK Virus Nephropathy After Kidney Transplantation. Transplant Direct. 2016;2(2):e64.

23. Mihatsch MJ. Polyomavirus nephropathy: a brief review with special emphasis on clinico-patholgical aspects. Prilozi. 2012;33:5-22.

24. Mathis AS, Egloff G, Ghin HL. Calcineurin inhibitor sparing strategies in renal transplantation, part one: Late sparing strategies. World J Transplant. 2014:4:57-80.

25. Monappa V, Prabhu R, Geetha V, Rao L, Susmitha M. Decoy cells in urine cytology: A useful clue to post-transplant polyoma virus infection. J Cytol. 2012;29:133.

26. Drachenberg CB, Hirsch HH, Ramos E, Papadimitriou JC. Polyomavirus disease in renal transplantation: review of pathological findings and diagnostic methods. Hum Pathol. 2005;36:1245-55.

27. Singh HK, Bubendorf $L$, Mihatsch MJ, Drachenberg CB, Nickeleit V. Urine cytology findings of polyomavirus infections. Adv Exp Med Biol. 2006:577:201-12.

\section{Submit your next manuscript to BioMed Central and we will help you at every step:}

- We accept pre-submission inquiries

- Our selector tool helps you to find the most relevant journal

- We provide round the clock customer support

- Convenient online submission

- Thorough peer review

- Inclusion in PubMed and all major indexing services

- Maximum visibility for your research

Submit your manuscript at www.biomedcentral.com/submit
Biomed Central 